\title{
Thermal response test for shallow geothermal applications: a probabilistic analysis approach
}

\author{
Francesco Tinti ${ }^{1}$, Roberto Bruno ${ }^{1}$ and Sara Focaccia ${ }^{1,2^{*}}$
}

\author{
* Correspondence: \\ sara.focaccia2@unibo.it \\ 'Department of Civil, Chemical, \\ Environment and Materials \\ Engineering - DICAM, University of \\ Bologna, 40131 Bologna, Italy \\ ${ }^{2}$ Centro de Recursos Naturais e \\ Ambiente - CERENA, Instituto \\ Superior Técnico, Av. Rovisco Pais 1, \\ 1049-001 Lisbon, Portugal
}

\begin{abstract}
Background: Thermal Response Test (TRT) is an onsite test used to characterize the thermal properties of shallow underground, when used as heat storage volume for shallow geothermal application. It is applied by injecting/extracting heat into geothermal closed-loop circuits inserted into the ground. The most common types of closed loop are the borehole heat exchangers (BHE), horizontal ground collectors (HGC), and energy piles (EP). The interpretation method of TRT data is generally based on a regression technique and on the calculation of thermal properties through different models, specific for each closed loop and test conditions.

Methods: A typical TRT record is a graph joining a series of experimental temperatures of the thermal carrier fluid. The proposed geostatistical approach considers the temperature as a random function non-stationary in time, with a given trend, therefore the record is considered as a 'realization', one of the possible results; the random nature of the test results is transferred to the fluctuations and a variogram modeling can be applied, which may give many information on the TRT behavior.

Results: In this paper, a nested probabilistic approach for TRT output interpretation is proposed, which can be applied for interpreting TRT data, independently of the different methodologies and technologies adopted. In the paper, for the sake of simplicity, the probabilistic approach is applied to the 'infinite line source' (ILS) methodology, which is the most commonly used for BHE.

Conclusions: The probabilistic approach, based on variogram modeling of temperature residuals, is useful for identifying with robust accuracy the time boundaries (initial time $t_{0}$ and the final time $t_{f}$ ) inside which makes temperature regression analysis possible. Moreover, variograms are used into the analysis itself to increase estimation precision of thermal parameter calculation (ground conductivity $\lambda_{g}$, ground capacity $c_{g}$, borehole resistance $R_{b}$ ). Finally, the probabilistic approach helps keep under control the effect of any cause of result variability. Typical behaviors of power, flows, and temperatures and of their interaction with the specific closed-loop circuit and geo-hydrological system are deepened by variogram analysis of fluctuations.
\end{abstract}

Keywords: Geostatistics; Thermal response test; Borehole heat exchanger; Ground thermal conductivity; Estimation variance; Borehole thermal resistance; Conditional probability distribution function

\section{Springer}

(c) 2015 Tinti et al.; licensee Springer. This is an Open Access article distributed under the terms of the Creative Commons Attribution License (http://creativecommons.org/licenses/by/4.0), which permits unrestricted use, distribution, and reproduction in any medium, provided the original work is properly credited. 


\section{Background}

\section{Introduction}

In recent years, there has been a noticeable increase of air conditioning systems coupled to shallow geothermal reservoirs (Sanner et al. 2003; Urchueguía et al. 2008; Lund et al. 2005; Spitler 2005). In fact, by installing appropriate 'ground heat exchangers' (closed loop) or wells (open loop), the underground is used as a seasonal storage of thermal energy, from which it is possible to extract heat in winter and cold over the summer (Schaetzle 1980).

Underground heat can be exploited through a heat transfer between soil and heat exchangers of different types and sizes. Among possible configurations, quite often used worldwide is the insertion of a $\mathrm{U}$ loop into the ground, submersed in filling material, namely the borehole heat exchanger (BHE) solution (Eskilson 1987). Underground is not a homogenous medium. In fact:

- ground has vertical and horizontal variation in composition and therefore properties;

- geology can have different horizontal variations, such as wedging, inclusions, and lenses.

When subjected to thermal phenomena, ground volume increases with time, and therefore, variations of the parameters of interest are expected; the type of variation encountered may be indicative of the specific geological structure.

The spatial variability of the ground properties and the space-time variability of hydrogeological conditions are specific to each case, and both are defined by geostatistical functions as variograms and drift (Chiles and Delfiner 1999). These properties affect the real power rate of each BHE and, consequently, the amount of energy extracted from/injected into the ground. The problem itself is complicated, due to underground anisotropies, temperature gradients, and heat transport processes, so that it is not an easy task to identify the underground thermal properties to be considered when designing (Witte and Van Gelder 2006; Bandos et al. 2011).

At the current state of technology, thermal response test (TRT) is the test for the characterization of ground thermal properties with the highest degree of accuracy, consisting in simulating the BHE real operation of heat injection/extraction for a limited time (Eklof and Gehlin 1996; Austin 1998). The TRT records the temperature response of the BHE to a constant heat injection or extraction. To provide a constant heat flux to the ground, the temperature difference between inlet and outlet and the fluid flow rate, measured by a flow meter, are held constant during the test. Therefore, the outputs of the TRT are the inlet $\left(T_{\text {in }}\right)$ and outlet $\left(T_{\text {out }}\right)$ temperatures of the heat carrier fluid as a function of time. The change in time of mean fluid temperature is directly related to the rock/soil thermal conductivity around the borehole. It is mainly used to estimate the overall effective thermal conductivity over the BHE depth. This mean value is associated to an effective thermal conductivity through an appropriate model describing the heat transfer into the ground, thus relating it to the thermal properties of the medium. The Kelvin solution for temperature of the ground surrounding the BHE of large depth-to-radius ratio modeled as an infinite line source (ILS) is the basis for estimating the thermal properties of the ground from TRT data (Ingersoll and Plass 1948; Mogensen 1983; Hellström 1991; Gehlin 2002). 
This approach is used as well in the design standards of the International Ground Source Heat Pump Association (Bose et al. 1985).

In recent years, the accuracy in identifying underground thermal properties by using the TRT increased, due to two reasons. Firstly, there have been improvements in technology related to TRT machine and accessories: power control (Lim et al. 2006; Mattson et al. 2008), use of temperature sensors and optical fiber cables along borehole depth (Fujii et al. 2010; Raymond et al. 2011; Acuña and Palm 2013), and possibilities to perform the TRT in different modes, such as step pulse, reversible mode, and heat pump simulation (Witte and Van Gelder 2006; Georgiev et al. 2006; Gustafsson and Westerlund 2010). Secondly, the analysis method, starting from ILS approximation, has been developed in many manners: addition of degrees of complexity - finite line source (Bandos et al. 2009) and cylindrical line source (Austin 1998); deep evaluation of specific problems, such as equivalent time for interrupted tests (Beier 2008), borehole thermal resistance (Marcotte and Pasquier 2008), temperature behavior into the grout (Raymond et al. 2011), influence of groundwater flow, and thermosiphon effect (Gehlin et al. 2003; Liebel et al. 2012); and numerical simulation (Signorelli et al. 2007; Zanchini and Terlizzese 2008; Schiavi 2009). In particular, groundwater movement dramatically influences heat exchange between ground and BHE, by adding convective phenomena to simple conductive heat transfer.

Recently, it is a common scientific thought that the uncertainty component of the test, mainly related to natural variability of several of the involved parameters, cannot be neglected, so that some statistical and probabilistic techniques have been set up, especially related to multi-step parameter estimation (Wagner and Clauser 2005; Bandos et al. 2011; Bozzoli et al. 2011), sensitivity analysis (Li and Lai 2012), and error analysis (Witte 2012).

In this framework, the shallow geothermal research group of DICAM Department developed an original probabilistic analysis approach, based on considering temperature measurements of TRT as a random function (RF). During the years, the practice has shown that the approach can be applied to many aspects of TRT analysis and measurements, increasing the degree of confidence of the results (Bruno et al. 2011; Mercuri et al. 2013; Focaccia et al. 2013).

In this paper, a review of the geostatistical approach applied to TRT analysis is introduced by referring to the traditional and more popular analysis methodology, the simplified graphical analysis based on the ILS theory; furthermore, it can be easily extended to more up-to-date or complex methodologies of TRT analysis.

\section{The state of the art: line source model analysis}

The thermal properties of interest for a borehole heat exchanger system are as follows: ground thermal conductivity $\left(\lambda_{\mathrm{g}}\right)$, ground volumetric heat capacity $\left(c_{\mathrm{g}}\right)$, borehole thermal resistance $\left(R_{\mathrm{b}}\right)$, and undisturbed ground temperature $\left(T_{\mathrm{g}}\right)$. All these parameters, necessary for the correct dimensioning of a BHE system, are regionalized variables in space or spacetime and can be modeled as realizations of random functions (Matheron 1971).

TRT works by injecting (or extracting) heat with constant power and by recording the temperature of thermal vector fluid. The values of equivalent/average thermal parameters of the ground volume affected by the test are computed according to the theory adopted. 


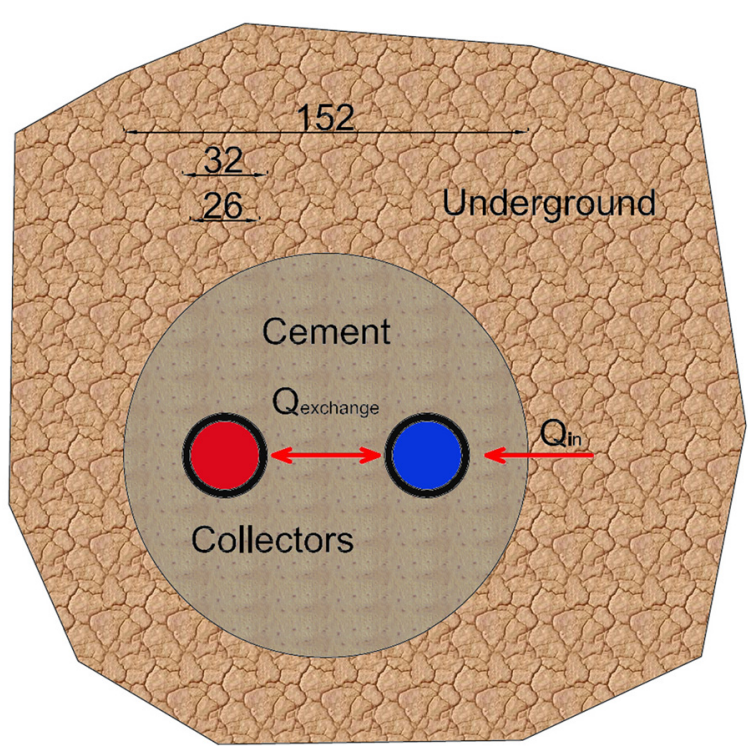

Figure 1 Section of a borehole heat exchanger. Ground thermal conductivity and volumetric heat capacity are related to the soil surrounding the borehole, while borehole thermal resistance is referred to as the effect of grouting both of the collectors.

Actually, TRT allows calculating an equivalent $\lambda_{\mathrm{g}}(\mathrm{W} /(\mathrm{m} \cdot \mathrm{K}))$ of the materials included in the volume affected by the heat exchanger during the test. The term 'equivalent' follows the definition given by Matheron to the value of a vector variable attributed to a finite volume, resulting from the application of a differential equation as Darcy for permeability or Fourier for thermal conductivity (Matheron 1967). Borehole thermal resistance $R_{\mathrm{b}}(\mathrm{m} \cdot \mathrm{K} / \mathrm{W})$ is the effective thermal resistance of the volume between the inner surface of collector, in contact with the thermal carrier fluid, and the outer surface of the borehole, in contact with the ground (Figure 1). It represents the resistance in exchanging heat between ground and thermo-vector fluid and can be higher or lower depending on material properties and geometry, as well as on quality of installation. In this paper, we assume that installation quality is optimum, so that grouting is homogeneous along the hole and the borehole section is regular (Sharqawy et al. 2009).

The ILS data analysis method uses the simplified equation of Hellström, Eskilson, and Mogensen (Eskilson 1987) to model temperature results of TRT, which turns into a line in the dimension of the time logarithm (Equation 1):

$$
T_{\mathrm{f}}(t)=b \cdot \ln t+a
$$

Under the quasi-stationary hypothesis:

$$
t_{0} \geq \frac{w \cdot r_{\mathrm{b}}^{2}}{d_{\mathrm{b}}}
$$

in which accuracy increases with parameter $w$.

First, a linear regression on experimental temperatures allows estimating the line parameters, the slope $b^{*}$ and the intercept $a^{*}$. Then $\lambda_{\mathrm{g}}$ is estimated from $b^{*}$ : 


$$
\lambda_{\mathrm{g}}^{*}=\frac{Q}{4 \cdot \pi \cdot H \cdot b^{*}}
$$

Afterwards, $R_{\mathrm{b}}$ is estimated from the intercept $a^{*}$, after choosing a guess value of $c_{\mathrm{g}}$ :

$$
R_{\mathrm{b}}^{*}=\frac{H}{Q} \cdot\left(a^{*}-T_{\mathrm{g}}\right)-\left(\frac{1}{4 \cdot \pi \cdot \lambda_{\mathrm{g}}^{*}}\left(\ln \frac{4 \cdot \frac{\lambda_{\mathrm{g}}^{*}}{\left(c_{\mathrm{g}}\right)^{G}}}{r_{\mathrm{b}}^{2}}-\gamma\right)\right)
$$

The current procedure, if certain conditions hold (no groundwater flow, no axial heat transport, and no trend in geology) and for a given BHE design (for example, single U), is based on a purely conductive model, with known boundary conditions, and on some hypothesis: injected power $Q$ must be constant, and borehole thermal diffusivity $d_{\mathrm{b}}$, undisturbed ground temperature $T_{g}$, and geometry $r_{\mathrm{b}}$ have to be considered spatially constant. Even accepting the model as proposed, a few remarks can be made:

- Starting guess values are needed at least for $t_{0}, d_{\mathrm{b}}$, and $t_{\mathrm{f}}$, whose choice is entrusted to the operator experience and normally not based on an objective quantitative measurement, unless the starting values were obtained by different tests (Witte and Van Gelder 2006). This implies that results are, up to a certain level, subjective.

- The results are affected by an uncertainty depending on the degree of likelihood of the hypotheses assumed mainly on the spatial and temporal constancy of parameters and variables, including the values of geometrical parameters as radius/length of the borehole; a quantitative evaluation of their uncertainty is missing or inadequate.

- There is a circular analysis concerning the current procedure for borehole thermal resistance identification: borehole thermal resistance $\left(R_{\mathrm{b}}\right)$ is a function of the borehole radius $\left(r_{\mathrm{b}}\right)$ and thermal diffusivity $\left(d_{\mathrm{b}}\right), R_{\mathrm{b}}\left(r_{\mathrm{b}}, d_{\mathrm{b}}\right)$, and is estimated using regression analysis which applies to steady state conditions, i.e., from a time actually identified by the inequality (Gehlin 2002). To identify this initial time, a tentative value of thermal diffusivity $d_{\mathrm{b}}{ }^{G}$ is requested, which means, implicitly, that a tentative value of borehole thermal resistance $R_{\mathrm{b}}{ }^{G}$ has been adopted.

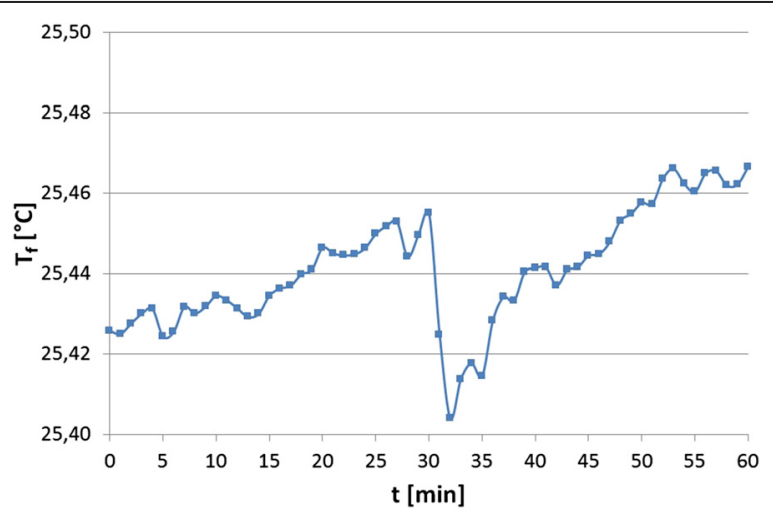

Figure 2 Evolution of thermal carrier fluid temperature in the time scale. 
A probabilistic approach is proposed, which is able to face similar issues satisfactorily by considering the fluid temperature as a RF in time domain (a 'stochastic process', following the terminology of time series analysis).

\section{Methods}

\section{The probabilistic analysis of a TRT: general concepts}

A typical TRT record is a graph joining a series of experimental temperatures of the thermal carrier fluid. A very smooth test is considered in the following image, but showing anyway some small fluctuations of average fluid temperature (Figure 2). In the following figures, the paper is presenting the temperature data set of a TRT carried out by ZAE Bayern (Germany) on a $195-\mathrm{m}$ double-U heat exchanger, subjected to a 9.5-kW constant power injection for a period of 3.5 days, previously selected as standard TRT in the IEA-ECES Annex 21 TRT Final Report and related publications (IEA ECES Annex 21 Thermal Response Test 2013; Focaccia et al. 2013).

By taking a look at Equation 1 (par. 2), the first immediate consideration is that the operator has to face a classical problem of parameter estimation (Van der Heijden et al. 2004), because the true value of service parameters, $b$ and $a$ of the model, can only be estimated, $b^{*}$ and $a^{*}$. An estimation error results, and it can only be handled as a random variable. A measurement of the estimation quality is simply given by the estimation error variance.

Moreover, the temperatures recorded by experimental TRT are actually influenced by several factors, and they fluctuate around an average value whose behavior should be the one stated by ILS theory if no systematic deviation is observed from theoretical conditions.

When repeating TRT records, therefore, the measured $T_{\mathrm{f}}$ profiles will not match exactly but show variations around an average temperature evolution. This is explained by the fact that secondary factors vary and cannot be controlled.

The proposed geostatistical approach considers the temperature $T_{\mathrm{f}}$ as a RF nonstationary in time, with a given trend (Equation 5). A classical residual model can be considered: the temperature is modeled as the sum of a mean function (the expected value), $m(t)$, deterministic, and a stationary random function (StRF), $Y(t)$, called

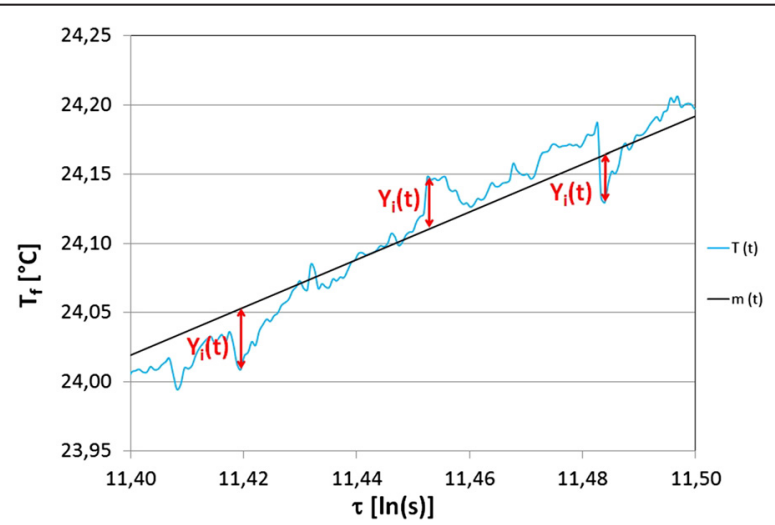

Figure 3 Evolution of $T_{\mathbf{f}}$ in $\boldsymbol{\tau}$. T(t) can be represented in each point as the sum of an average $m(t)$ and a fluctuation $Y(t)$. 
fluctuation or residual, with zero mean (Figure 3, Equation 5). The fluid temperature mean function, representing the average behavior of the RF, is defined according to the ILS theory:

$$
\begin{aligned}
& T(t)=m(t)+Y(t) \\
& E[T(t)]=m(t)=a+b \ln (t) \quad t>t_{0}
\end{aligned}
$$

A TRT record is then considered as a 'realization' of the non-stationary RF, one of the possible results. The random nature of the test results is transferred to the fluctuations (Figure 3).

The variogram of fluctuations (Equation 7) is:

$$
\gamma(h)=\frac{1}{2} \operatorname{var}\{T(t+h)-T(t)\}=\frac{1}{2} E\left[(Y(t+h)-Y(t))^{2}\right]
$$

In practice, the experimental variogram is computed on residuals obtained by subtracting the estimated mean from recorded temperatures, $Y^{*}(t)=T(t)-m^{*}(t)$. The mean can be estimated by a classic regression method, which, for the aims of variogram analysis, is considered quite robust because there is a large number of data. Therefore, the variance of experimental residuals is very similar to the theoretical fluctuations' variance. Consequently, the experimental variogram is very stable and insensitive to the quality of the mean estimation.

In Figure 4, the experimental and model variograms of fluctuations are presented. The stationary hypothesis is acceptable, and the model is adjusted with three nested structures: a nugget, a sphere with a range of $41 \mathrm{~h} 40 \mathrm{~min}$, and a Gaussian with a range of $7 \mathrm{~h}$. A good correlation is shown for time lags up to ten and more hours.

\section{Evaluating time boundaries through probabilistic approach}

The time domain in which to analyze test data is an important issue because test accuracy and target parameters can vary significantly when changing initial and final time (Lim et al. 2006).

Initial time $t_{0}$, from which the test values are considered, is necessary because the ILS theory is satisfactorily approximated only from that point on. In the classical approach, the actual $t_{0}$ for the regression analysis is computed as a multiple of the ratio between the borehole radius $r_{\mathrm{b}}$ and borehole thermal diffusivity $d_{\mathrm{b}}$, following the relationship

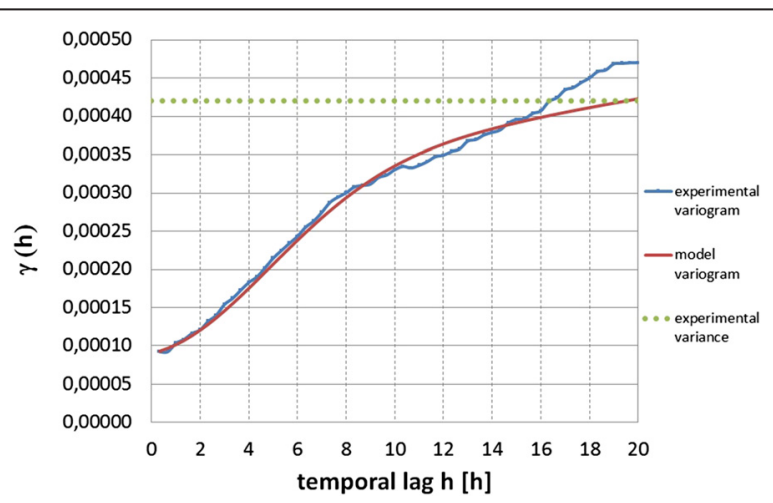

Figure 4 Variogram of fluctuations $Y$, experimental (blue) and model (red). 
(Equation 2). A theoretical model and specific hypotheses, based on the Taylor series, state that the proportionality coefficient must be greater than five, $w>5$, for getting a satisfactory approximation. For improving the accuracy of ILS theory results, greater values are necessary; for instance, $w>20$ increases the accuracy to $2.5 \%$.

It is therefore additionally proved that $Q$ values affect $t_{0}$ (Signorelli et al. 2007). If higher $Q$ is applied during TRT, the curve behavior will reach a linear trend earlier than when lower $Q$ is applied. For this reason, the initial hypothesis that any borehole of the same radius and same thermal properties which identifies the same initial time introduces an error because it makes the analysis test-independent when actually it is test-dependent.

On the other hand, target variables, i.e., the thermal parameters, are very sensitive to the choice of coefficient $w$ than to $t_{0}$. In Figure 5, the percentage variations of $\lambda_{\mathrm{g}}$ and $c_{\mathrm{g}}$ are shown when varying $w$ in the interval (5 to 20) stated by the classic ILS theory.

The probabilistic approach can help to solve this issue by introducing the use of a moving windows (MW) method which is able to control the existence of steady state conditions by stabilizing the regression line slope $b$. The underlying idea is that when the slope floats more than a predefined value, then the initial time is identified because the theory is no longer valid.

Concerning the final time to stop the test $t_{\mathrm{f}}$, there is no problem of applicability of theory but of parameters' stability and test costs. As the cost of a test increases with increasing test duration, there is a desire to have a prior estimate of the minimum test duration that yields valid results. Many authors proposed a recommended minimum duration, based on practical field experience (Gehlin 1998; Austin 1998). Other authors developed a method to estimate the minimum test duration based on the borehole and soil properties (Beier and Smith 2003). The probabilistic criterion proposed consists of finding a consistent value based on a forward regression (FR) procedure: when the slope value does not show a meaningful change by an increment of the test time, it can be assumed that the heat transfer in the underground follows the predicted evaluation model, and the evaluation time is large enough to provide for the statistical precision desired.

\section{Identifying starting point through estimation variance}

The choice of $t_{0}$ following the classical deterministic relationship is site-independent once the design values of borehole parameters and of power are fixed. We know that it

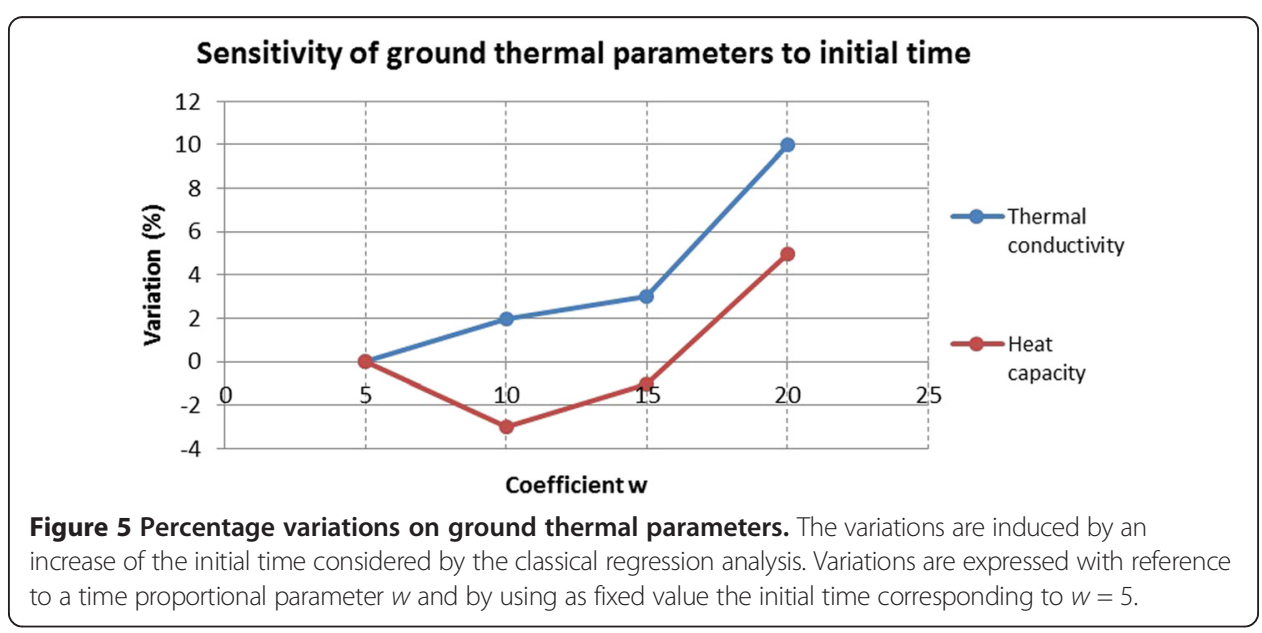


is an uncertain value given the uncertainty and variability of independent parameters; therefore, it must be checked if it is coherent with the theory.

A probabilistic approach is proposed for checking the consistency of $t_{0}$ with the local causes of variability and uncertainty. This technique rests on the reasoning that it is quite difficult to demonstrate when ILS theory starts to be valid, but it can be verified at any time if there is coherence between assumptions and actual results. The methodological point of view considers that, in the geo-resources field, a model hardly can be proven (to prove that it is true), but it can be falsified (to prove that it is false) (Matheron 1978).

Operationally, the idea is the coherence of the results obtained by applying a model, a sort of cross-validation between the expected and actual precision of estimate. In fact, the normalized error must guarantee $E\left(e^{2} / \sigma_{e}^{2}\right)=1$. Here, the estimation variance is given by the theoretical expression by applying the model, and the error is given by the difference between the value deduced by adopting that $t_{0}$, considered as the true value, and some estimate of it.

Moving windows with constant $t$-length intervals are considered, on which slope and intercept are estimated by linear regression. In the following, only parameter $b$ is considered, being more convenient as it depends just on thermal conductivity and its estimation has a better quality than $a$.

The regression is a linear estimator whose weights depend only on time logarithm. For instance, in the case of the slope regression on $n$ pairs $T-\tau$, the regression and its weights can be expressed by:

$$
\begin{aligned}
b^{*} & =\sum_{\alpha=1}^{n} v_{\alpha}^{b} T_{\alpha} \\
v_{\alpha}^{b} & =\frac{\tau_{\alpha}-\bar{\tau}}{n \cdot \sigma_{\tau}^{2}}
\end{aligned}
$$

where $T_{\alpha}$ is the temperature data registered at the times $t_{\alpha}$ and $v_{\alpha}$ their weights; $\tau$ and $\sigma_{\tau}^{2}$ are the mean and variance of logarithms of sample times $\tau_{\alpha}$.

Being a correct linear estimator, the estimation variance $\sigma_{e}^{2}$ is expressed by the variogram of temperature fluctuations:

$$
\sigma_{e}^{2}\left(b^{*} \rightarrow b\right)=-\sum_{\beta=1}^{n} \sum_{\alpha=1}^{n} v_{\beta}^{b} v_{\alpha}^{b} \gamma\left(t_{\alpha}-t_{\beta}\right)
$$

Remark that the weights $v_{\alpha}{ }^{b}$ are independent of the variogram model because they are simply deduced by the regression method. Assuming the estimation error as a Gaussian variable, a small ratio between the experimental error and the standard deviation $|e| / \sigma_{e} \leq 1$ means that the ILS theory can be considered applicable. In effect, the interval given by the estimated value \pm the error standard deviation, $b^{*} \pm \sigma$, has approximately $68 \%$ chance of containing the true value $t_{0}$. Graphically, we can observe that if the true slope $b$ does not fall inside the acceptable variability interval at a point $t>t_{0}$, we can conclude, by simplifying, that there is no sufficient coherence between the $t_{0}$ chosen and the deduced $b$ value.

The approach can be also applied to justify the choice of a new $t_{0}{ }^{p}$ coherent with the probabilistic model, coinciding with the time $t$ where the line of true slope value crosses to exit the possible theoretical variability band. In the case study shown, the 


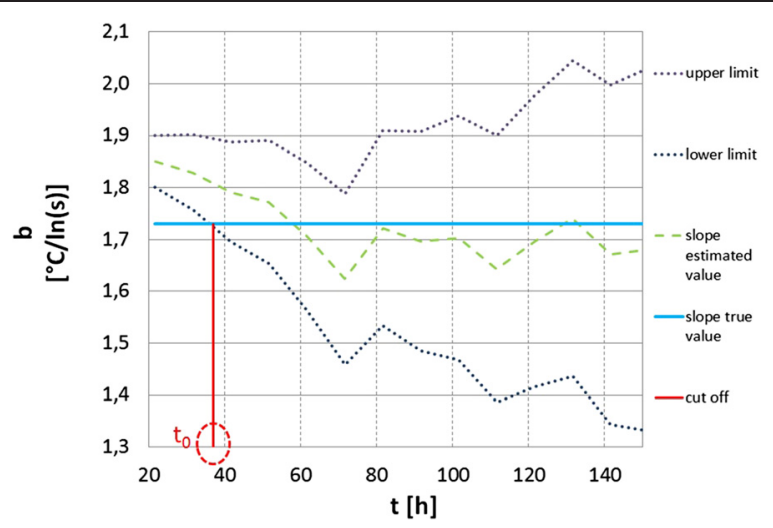

Figure 6 Evaluation of initial time $\boldsymbol{t}_{0}$. True slope value (blue horizontal line) crosses and exits from the error standard deviation band (blue dots and purple dots). The green line represents slope values estimated by moving windows of $10 \mathrm{~h}$. The intersection point identifies the initial time $t_{0}$, visible through the red vertical line.

windows' length of $10 \mathrm{~h}$ has been chosen by taking into account the actual variogram range (Figure 6).

In this procedure, there is a possible circularity because a guess initial time $t_{0}{ }^{G}$ is indirectly needed. In effect, the procedure is fed by the slope value $b$ obtained by the traditional method and considered as the true value. Therefore, a sensitivity analysis of $t_{0}{ }^{p}$ has been made when variations of the initial guess $t_{0}{ }^{G}$ are considered (Figure 7). The problem proves to be irrelevant because the meaningful variation of $t_{0}{ }^{G}$ does not affect either the variogram model or the $t_{0}{ }^{p}$ probabilistic identification as shown in the figure. This high stability of $t_{0}{ }^{p}$ makes the procedure proposed very affordable.

Some properties of the proposed probabilistic approach for checking the coherence of the initial time deduced by classic deterministic relationships are as follows:

1. It is a 'non-parametric' procedure because it relies only on experimental data, while the traditional method needs the values of $r_{\mathrm{b}}, d_{\mathrm{b}}$, and $Q$.

2. It highlights that the result in principle is 'site/test-dependent', i.e., it can take into account any fact that makes every borehole/test different from each other, even if they adopt the same $r_{\mathrm{b}}, d_{\mathrm{b}}$, and nominal power.

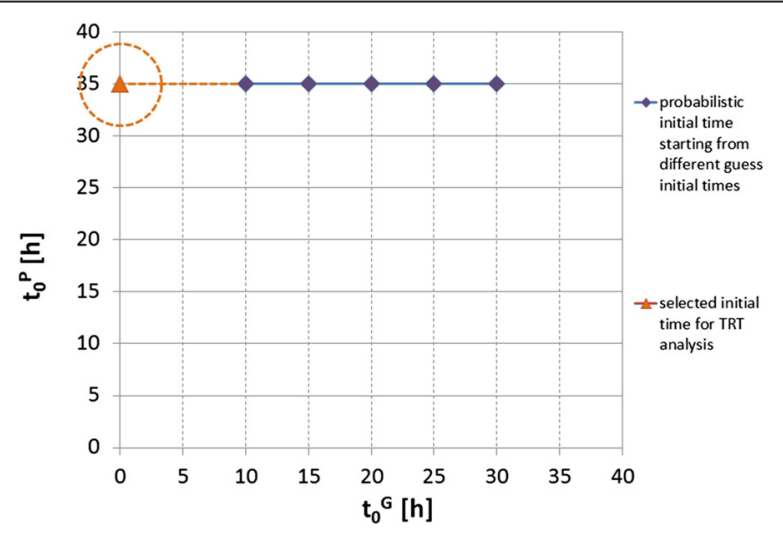

Figure 7 Sensitivity of the probabilistic procedure. Sensitivity of the probabilistic procedure for calculating the initial time of steady state evolution of temperature depending on variation of guess initial time. 
3. The procedure is based on and justified by an objective criterion.

\section{Identifying ending point through estimation variance}

No theoretical meaning is attributed to the test final time $t_{\mathrm{f}}$. The problem is operational, and the point is to decide when to stop testing and why.

An important point is the stability of conditions necessary for the application of the ILS theory. Quite often at the end of the test (3 days), there are variations in $Q$ and $T_{\mathrm{f}}$, which affect $\lambda_{\mathrm{g}}$ evaluation. In practice, $t_{\mathrm{f}}$ variations affect the numerical results of $\lambda_{\mathrm{g}}{ }^{*}$. Potentially, this variability could question the validity of the ILS theory at the end of the test, mainly because power can be not sufficiently constant but also because the volume interested by the TRT grows in time, and consequently, the equivalent values of thermal parameters change, given that the support of the equivalent parameters changes. Currently, there are no shared criteria for $t_{\mathrm{f}}$ calculation. Techniques based on result stability of moving windows are questionable when temperature fluctuations increase with time.

The proposed procedure relies again on the exploitation of estimation variance $\sigma_{e}^{2}$ (Equation 9) of slope graphical parameter, but this time, there are no theoretical hypotheses to be verified or applied. A methodology has been set up for justifying objectively the decision concerning when to stop TRT, such as when the precision of thermal property estimation is sufficient. The problem shifts on the computation of estimate quality, in practice on the $\sigma_{e}^{2}$.

The proposal of FR is to consider time intervals of increasing length, in which the low end is fixed in time $t_{0}$ and the other end increases systematically.

For each interval, the slope is computed, always by linear regression. Increasing windows' length increases the confidence of the estimate $b^{*} \cdot t_{\mathrm{f}}$ is chosen when estimation quality, as measured by standard deviation, $\sigma_{e}^{2}$, reaches a level considered sufficient/satisfying (Figure 8).

The procedure is simple even if a bit time consuming given the high number of data to take into account. The methodology has two interesting issues:

1. The final time is objectively chosen on a meaningful quantitative criterion: once agreed on the precision level to reach, $t_{\mathrm{f}}$ is identified. It must be highlighted that at

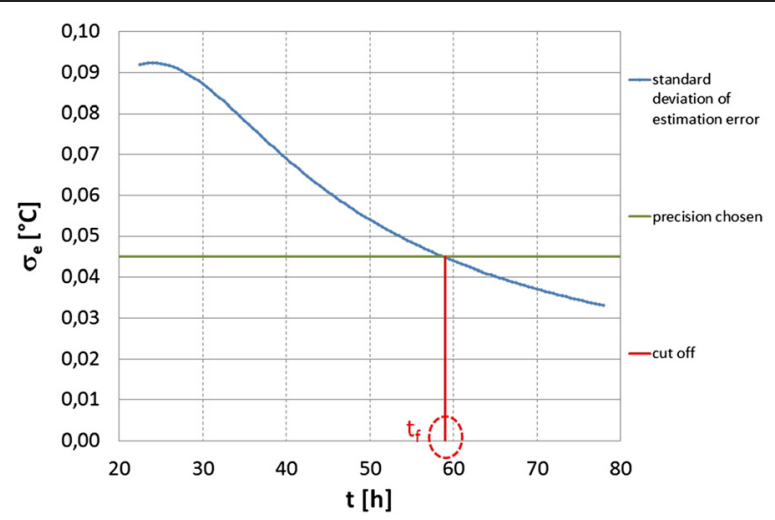

Figure 8 Decreasing evolution of the standard deviation (blue line) calculated on windows of increasing dimension in the logarithmic time. The green line represents the precision limit chosen. The intersection between the two lines identifies the minimum final time $t_{f}$ necessary to reach the precision required, visible through the red vertical line. 
present the subjectivity level is high, because no shared solutions have been proposed for $t_{\mathrm{f}}$ choice.

2. An interesting advantage of the procedure proposed is that it could be possible to state when to stop the test with an acceptable advance (e.g., after the second day). $t_{\mathrm{f}}$ is no longer to be chosen during measurements by continuously computing the slope regression on MW and by checking a stability criterion. In effect, the standard deviation curve (the blue one in Figure 8) can be drawn by knowing just the variogram model, because $\sigma_{e}^{2}$ is independent from the measured values. The variogram can be modeled after the approximately 45 to $50 \mathrm{~h}$ of running the TRT; this means that once the precision required is decided, i.e., the fixed red line in Figure 8, the future $t_{\mathrm{f}}$ is identifiable.

The main operational drawback of the method is the very high number of points necessary to compute $\sigma_{e}^{2}$ according to Equation 9. For example, 2 days of measurements, each $60 \mathrm{~s}$, means 2,880 data. From the theoretical point of view, it is important to verify the validity of the variogram model at this scale of very large time intervals.

\section{Estimating ground thermal conductivity through drift}

Ground thermal conductivity is deduced by the ILS relationship from the slope parameter $b$ of $T-\ln (t)$ line, as written in paragraph 2. The temperature drift, $D(h)$, is the mean value of the difference (increments) between temperatures with a time distance, the lag, equal to $h=\ln \left(t^{\prime}\right)-\ln (t)$ (Figure 9). The proposed method does not change the general $\operatorname{logic}$ of the approach, but the way of estimating $b$. As the application of the drift is in time-log space, with data density progressively increasing along the $t$-axis, a declustering selection technique is needed prior to the drift calculation; it consists of a random selection method, which allows to obtain a final data set, with all points regularly spaced from each other (Focaccia et al. 2013).

In principle, the 'drift method' has a couple of advantages over the classical method:

1. The estimation filters the intercept $a$, and this fact allows for a more precise estimation of the slope $b$.

2. The separation of the estimations of the slope from that of the intercept allows for better control of each regression.

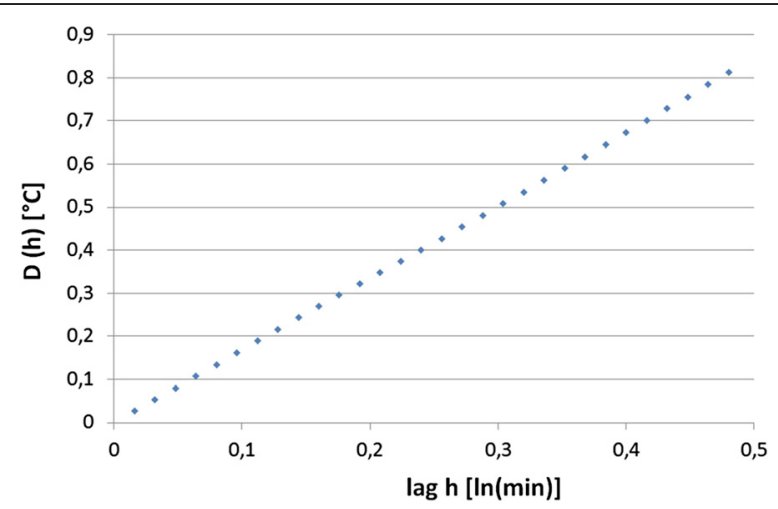

Figure 9 Experimental drift of temperature in the space of time-log increments. The lag dimension is the increment of time logarithm, $h=\Delta \tau$. 
The drift is a line passing through the origin; therefore, the regression weights are simply proportional to the independent variable, i.e., the time-log lag (Focaccia et al. 2013).

The intercept $a$ of the line representing the mean fluid temperature in time-log space $\{\tau\}$ is also required. This is obtained sequentially by a new mono-parameter linear regression based on fluid temperatures $T_{\mathrm{f}}$ in the time-log space $\{\tau\}$ and conditioned by the slope estimate already obtained by the regression on the experimental drift (Figure 10).

In practice, the parameter obtained by this regression can be calculated following the form of a linear estimator (Equation 10):

$$
D\left(\Delta \tau_{j}\right)=D(j \delta)=E\left[T\left(\ln t+\Delta \tau_{j}\right)-T(\ln t)\right] \cong \frac{\sum_{\alpha=1}^{n_{c}(\Delta t)}\left[T\left(\ln t_{\alpha}+\Delta \tau_{j}\right)-T\left(\ln t_{\alpha}\right)\right]}{n_{c}\left(\Delta \tau_{j}\right)}=D^{*}\left(\Delta \tau_{j}\right)
$$

It has been shown that the precision of estimates of the slope $b$ by the drift method is always higher than the precision given by the classic method (Focaccia et al. 2013). This comparison is possible thanks to the estimation variance computation by Equation 9.
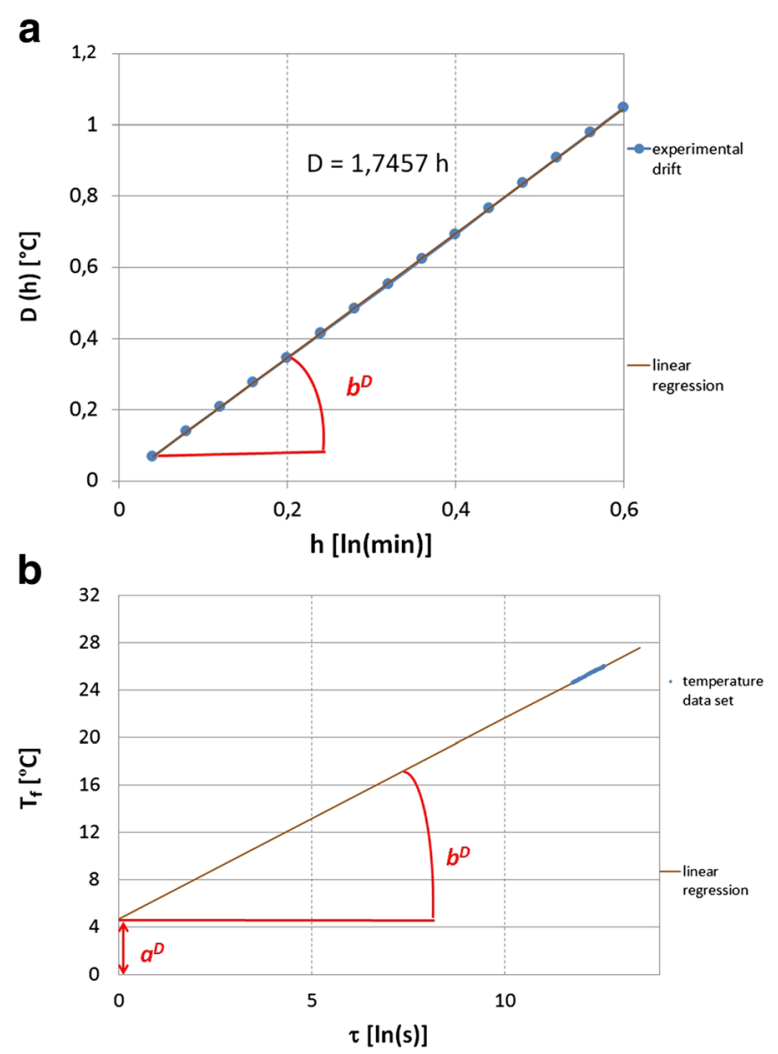

Figure 10 Two-step estimation. (a) Slope by regression on drift. (b) Intercept by conditional regression on temperatures. The lag dimension is the increment of the time logarithm, $h=\Delta \tau$. 


\section{Estimating ground volumetric heat capacity and borehole thermal resistance through conditioning}

Once $\lambda_{\mathrm{g}}$ is calculated, it is then possible to calculate $R_{\mathrm{b}}$. Normally, the procedure first consists in the choice of a fixed guess value for thermal capacity $c_{\mathrm{g}}{ }^{G}$ and then, through Equation 4, the calculation of the borehole thermal resistance. This calculation is performed deterministically and overall by imposing a tentative value of $c_{\mathrm{g}}$, which is chosen as an average for the soils involved. On the contrary, it is possible to fix borehole thermal resistance (based on design parameters of borehole) and then to find ground volumetric heat capacity. This is generally not done in common practice, mainly because of the major importance of verifying if the borehole thermal performance is similar to the project value or not, due to accidents occurring during the installation procedure (inclined borehole, etc.) (Gehlin 2002).

Anyway, the random choice of ground volumetric heat capacity based on literature values can lead to non-negligible errors (10\% to 15\%) (Witte 2012). In order to increase confidence of TRT, some coupled parameter estimations have been made, mainly based on finite element models and coupling thermal conductivity with volumetric heat capacity (Wagner and Clauser 2005).

The methodology proposed does not use guess values but makes a joint conditional estimation of $R_{\mathrm{b}}$ and $c_{\mathrm{g}}$ by adopting a joint a priori probability distribution; the limits of marginal distributions are comprised within the variability range: i) calculated numerically on borehole parameters and grouting properties for $R_{\mathrm{b}} \in\left(R_{\mathrm{b}}{ }^{\text {inf; }} ; R_{\mathrm{b}}{ }^{\text {sup }}\right)$ and ii) obtained by the bibliography for $c_{\mathrm{g}} \in\left(c_{\mathrm{g}}\right.$ inf $; c_{\mathrm{g}}$ sup $)$. We then consider a conditioning relation between the two parameters, and we calculate the optimal values of both of them (Focaccia et al. 2013).

Conditioning relation reduces the variability domain of bivariate probability law by one dimension and identifies a sub-domain $L$ of existence of a couple of possible values for parameters based on TRT measures. The new extremes $\left(R_{\mathrm{b}}^{{ }^{L m i n}} ; R_{\mathrm{b}}{ }^{L \max }\right),\left(c_{\mathrm{g}}{ }^{{ }_{\mathrm{min}}} ; c_{\mathrm{g}}{ }^{L \max }\right)$ are obviously included within the original existing range (Figure 11):

$$
\left(c_{\mathrm{g}}^{L \min }, c_{\mathrm{g}}^{L \max }\right) \subseteq\left(c_{\mathrm{g}}^{\text {inf }}, c_{\mathrm{g}}^{\text {sup }}\right) \quad\left(R_{\mathrm{b}}^{L \min }, R_{\mathrm{b}}^{L \max }\right) \subseteq\left(R_{\mathrm{b}}^{\text {inf }}, R_{\mathrm{b}}^{\text {sup }}\right)
$$

The sub-domain, which derives from the conditioning relation, identifies a conditional probability distribution. The probability distribution function (PDF) of the service parameter $p$ is the probability distribution of the bivariate PDF conditional to the domain $L$.

Here follows the equation of conditional distribution and its exemplification by considering independent the two variables (Focaccia et al. 2013):

$$
\begin{aligned}
& \left(c_{g}^{L}, R_{b}^{L}\right): c_{g}, R_{b} \in L \Rightarrow R_{b}^{L}=-\frac{\omega_{1} p+\omega_{3}}{\omega_{2}} \Leftrightarrow c_{g}^{L}=e^{p} \\
& f(p)=f_{c_{g}, R_{b} \in L}=\frac{f\left(c_{g}^{L}, R_{b}^{L}\right)}{\int_{L} f\left(c_{g}^{L}, R_{b}^{L}\right) \mathrm{dL}}
\end{aligned}
$$

Optimal value of the couple ground volumetric heat capacity-borehole thermal resistance results simply from their conditional expectation, by using the expected value of service parameter $p: m_{p}=E(p)=\int p \cdot f(p) d p$. Remark that no guess values are needed and 

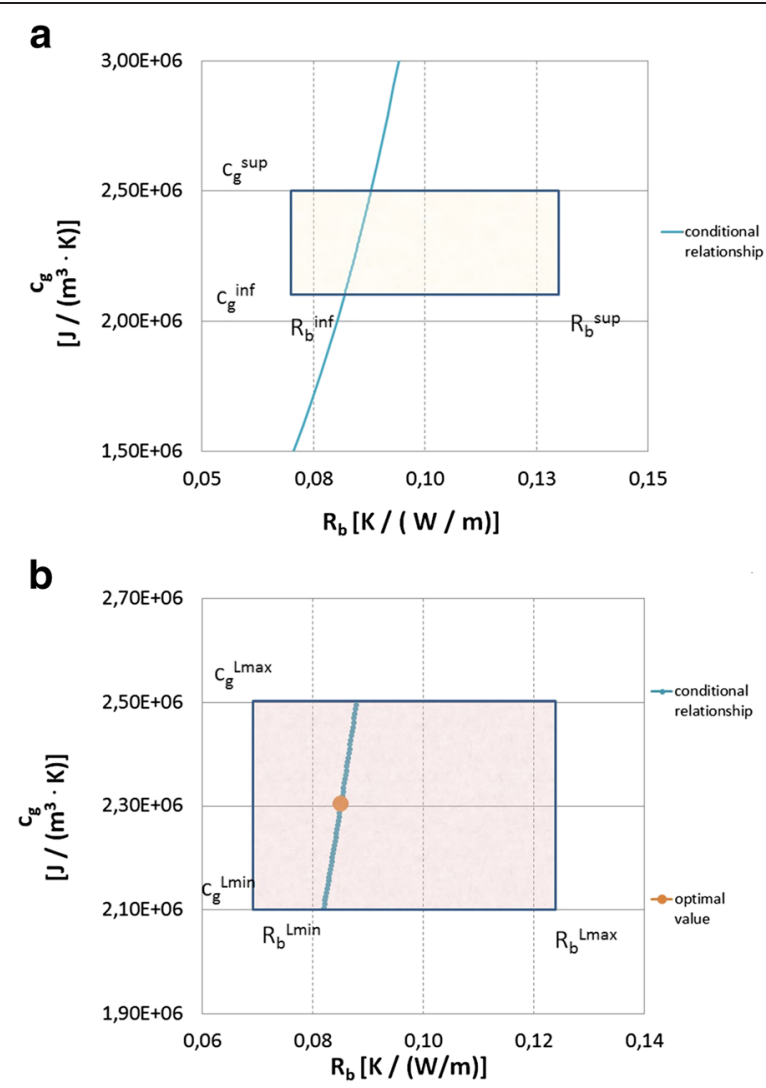

Figure 11 Borehole thermal resistance and ground volumetric heat capacity relationship. Only the couple of values falling inside an interval of admissible min-max values can be considered for conditional estimation. A validity area is identified: (a) whole curve inside and outside limit area; (b) zoom on the validity area and focus on optimal value obtained by conditional estimation.

that the couple respects both the range of possible values and the constraining relationship between them.

\section{Controlling machine-system operation through variograms}

TRT results are test/site-dependent, machine-dependent, and operation-dependent. In fact, the geological stratigraphy and hydrogeological properties, besides modifying the ground thermal parameters, condition the operation of a given TRT equipment. The TRT power can be supplied by different systems (e.g., heat pump and various type of boilers), and heat is exchanged differently depending on the circulation fluid. The problem of power constancy has been deeply analyzed by many authors, and a great literature exists to evaluate physical meanings of the power fluctuations (Witte 2012). When the option is available, the test can be executed in extraction or injection mode and the equipment operates quite differently (Witte and Van Gelder 2006). An analysis of variability and correlation among TRT parameters helps in checking, quantifying, and understanding the system operation and the possible impact on correctness and confidence of results.

The presence of an aquifer can affect significantly the operation of a TRT. An analysis of fluctuation of mean fluid temperatures by variogram can check and quantify how the system reacts (Mercuri et al. 2013) (Figure 12). 


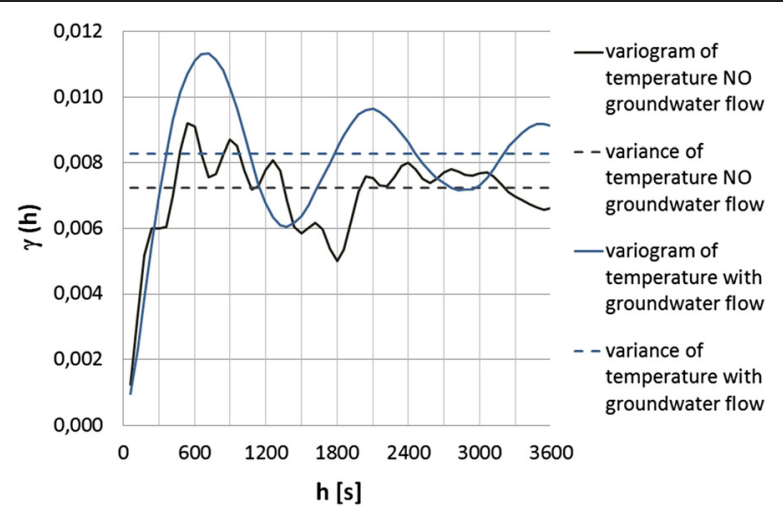

Figure 12 Experimental variograms of mean temperature fluctuations of fluid in the presence or absence of groundwater flow.

Power is variant in time so that power fluctuations must be taken into account in the calculation. Moreover, the fluctuations are not necessarily a 0-mean random noise; they could mask a trend or a bias, which will affect directly the key parameters' estimates. The common practice is to monitor injected power data and then to find thermal parameters that will best fit the data with the power signal registered, including the recovery phase, if present.

Power is dependent on temperature variations, being a function of the difference between inlet and outlet temperature, so that power fluctuations have to be taken into account to fully understand the nature of test response. In this case, too, the probabilistic approach can give a contribution. Firstly, it is necessary to study three independent variables (flow, inlet temperature, outlet temperature). They have very different time variability as shown by their fluctuation variograms (Mercuri et al. 2013) (Figure 13).

While the fluid flow does not show a periodic structure, the power shows it (Figure 14); therefore, it is indirectly confirmed that there is no correlation between the variability of fluid flow (unstructured) and power (structured).

Regarding comparison between injection and extraction modes' precision, the use of variograms can give a contribution, by showing operational behavior through the sill value and the variogram model (Mercuri et al. 2013).

The variogram analysis shows how the injection mode gets absolutely more precise estimates than the extraction mode; in fact, in injection mode, the short-term periodic component is prominent, the time range is infinite, and the sill is almost half that in the extraction mode (Figure 15).

In conclusion, by using a variographic study, it is possible to quantify how precise TRT data recording is and how much is influenced by external and boundary conditions; therefore, it is possible to associate to the analysis a measure of the reliability of the results.

\section{Results and discussion}

This work has introduced and summarized the provision given by a probabilistic approach to TRT analysis, in most cases by adopting a geostatistical point of view.

In general, many issues of the test data processing refer to uncertain parameters or to decisions based on uncertain parameters. 

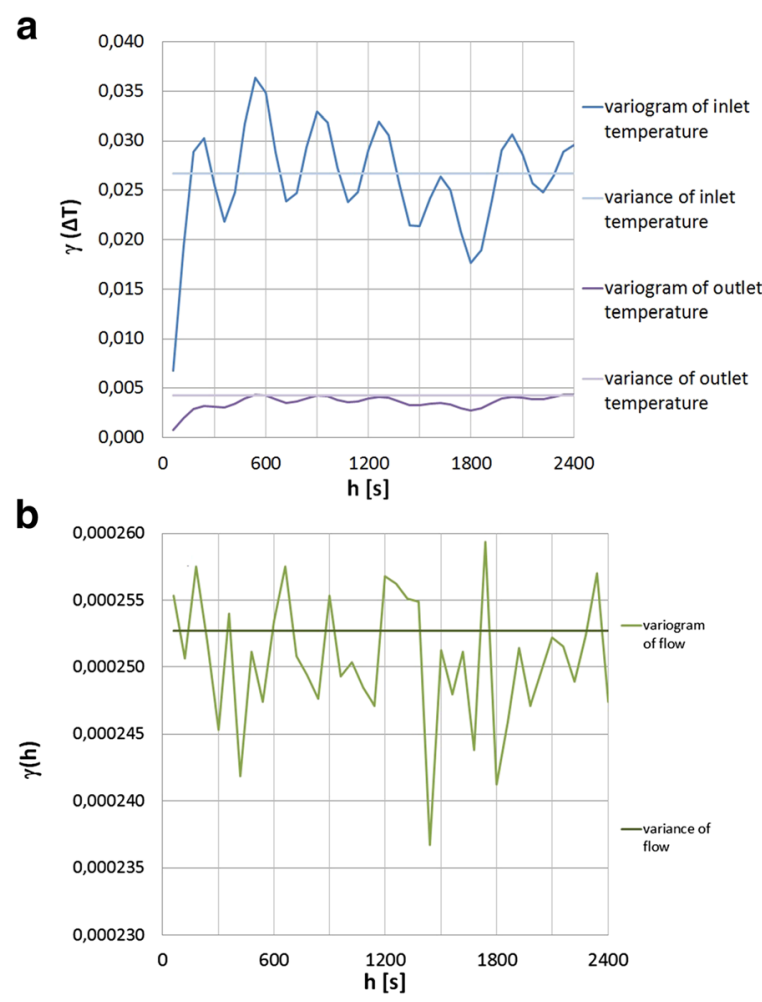

Figure 13 Experimental variograms of fluctuations of (a) inlet and outlet fluid temperature and (b) fluid flow.

Most of unsolved or unchecked issues of TRT can be evaluated, interpreted, and solved simply by the characterization of fluctuations around the average behavior of the fluid temperature, as depicted by the ILS theory. Fluctuations show what is happening around the test, and their variogram is useful for reducing subjective choices and quantifying the results' precision. In fact, thanks to variograms of temperature fluctuations, the estimation variances $\sigma_{e}^{2}$ of the key parameters of interest can be computed independently of the methodology adopted, and underground thermal properties can be identified efficiently. It is noteworthy that here the geostatistic tools are used for

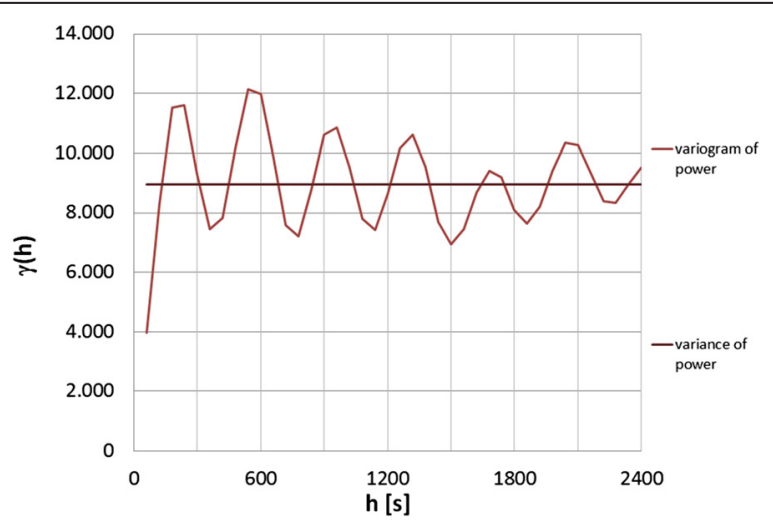

Figure 14 Experimental variogram of fluctuation of power. 


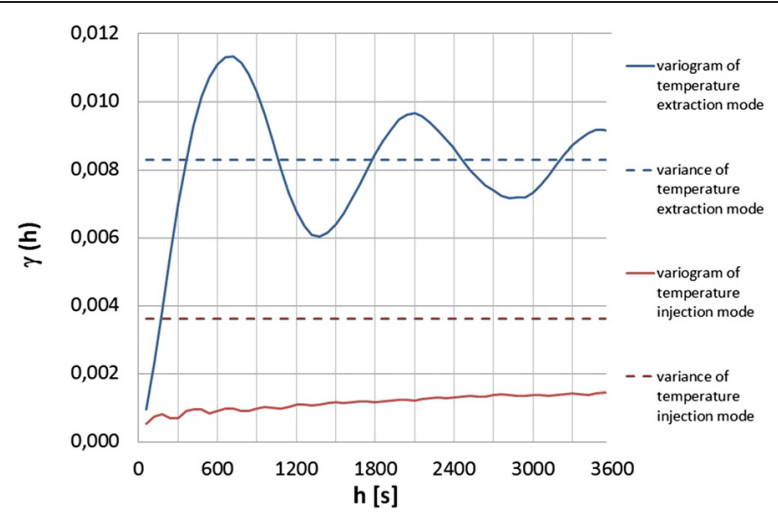

Figure 15 Experimental variograms of mean temperature fluctuations of fluid in TRT extraction and injection mode.

characterization and study of time variability of TRT records, and not for spatial or temporal estimation by kriging.

In particular, proposals have been made for checking the coherence of initial time $t_{0}$, for computation of final time $t_{\mathrm{f}}$, for improving and simplifying the estimation thermal ground conductivity $\lambda_{\mathrm{g}}$, for making more objective and congruent the joint estimation of thermal capacity $c_{\mathrm{g}}$ and borehole resistance $R_{\mathrm{b}}$, and for identifying and quantifying the effect of power time variability on TRT results.

i) The approach for checking the coherence of $t_{0}$ with the test-dependent causes of variability is based on the MW strand and on $\sigma_{e}^{2}$ exploitation. Namely and differently by the classical deterministic framework, it is non-parametric and site/test-dependent. At the moment, the approach looks efficient and can also be used to define an initial time more consistent with actual data.

ii) The proposal of $t_{\mathrm{f}}$ identification is based again on $\sigma_{e}^{2}$, but in this case, the result is data-independent, once the variogram is available. Each TRT operator is able to decide in advance when to stop the test, because the precision attained is sufficient.

iii) The drift method is very simple and in principle guarantees a better estimation of thermal conductivity than the traditional method. In numerical terms, the precision is similar when a record of hundreds of thousands of measurements is available.

iv) The conditional estimation concerning the calculation of ground volumetric heat capacity coupled to borehole thermal resistance makes possible to obtain a couple of values independent of subjective guess values but always coherent with constraining relationship. These values look more reliable and more consistent and closely related to the real test.

v) The TRT control through parameter fluctuations can allow identifying, quantifying, and controlling of specific variation effects caused by underground, climate conditions and machine-borehole interaction and not visible by simple record analysis.

\section{Conclusions}

In conclusion, the geostatistical approach proposed is able to take into account the irregular component of TRT experimental records and of results following their processing, interpreted as realizations of random functions. This approach allows also 
highlighting the nature of estimate of thermal parameters derived. New insights and new ideas are proposed on how to improve or solve classical issues of the test. Even if applied to the most popular methodology of TRT analysis and to a simplified case, the probabilistic approach seems able to be easily adapted also for the processing of TRT data by more advanced methodologies.

Future works will include the application of the method on additional TRT case studies, with different working conditions, technology advancement, and machine and sensor precision. The long-term goal is to improve the standardization of TRT and of its data analysis.

\section{Abbreviations}

BHE: borehole heat exchanger; FR: forward regression; ILS: infinite line source; MW: moving windows; PDF: probability distribution function; RF: random function; StRF: stationary random function; TRT: thermal response test.

\section{Competing interests}

The authors declare that they have no competing interests.

\section{Authors' contributions}

FT carried out all the necessary traditional and geostatistical studies and calculations for the TRT data test presented in the paper, participated in the sequence alignment, realized the bibliographic research and drafted the manuscript. RB proposed the realization of the paper, participated in the study and checked the congruence between theory and calculation; SF participated in all the geostatistical calculations, participated in the draft of the manuscript, participated in the bibliographic review and controlled the manuscript research and submission. All authors read and approved the final manuscript.

\section{Acknowledgements}

We want to thank the entire Annex 21 IEA-ECES group for the precious support in the deepening understanding and knowledge improvement of thermal response test theory and practice.

Received: 9 January 2015 Accepted: 23 February 2015

Published online: 31 March 2015

\section{References}

Acuña J, Palm B (2013) Distributed thermal response tests on pipe-in-pipe borehole heat exchangers. Appl Energy 109:312-320

Austin WA (1998) Development of an in situ system for measuring ground thermal properties, M.S. thesis. Oklahoma State University, Stillwater, OK, USA, p 177

Bandos TV, Montero Á, Fernández E, Santander JLG, Isidro JM, Pérez J, Fernández de Córdoba PJF, Urchueguía JF (2009) Finite line-source model for borehole heat exchangers: effect of vertical temperature variations. Geothermics 38(2):263-370

Bandos TV, Montero Á, Fernández de Córdoba PJF, Urchueguía JF (2011) Improving parameter estimates obtained from thermal response tests: effect of ambient air temperature variations. Geothermics 40(2):136-143

Beier RA, Smith MD (2003) Minimum duration of in-situ tests on vertical boreholes. ASHRAE Trans 109(2):475-486

Beier RA (2008) Equivalent time for interrupted test on borehole heat exchangers. Int J HVAC R Res 14:489-503

Bose JE, Parker JD, McQuiston FC (1985) Design/data manual for closed loop society of heating, refrigerating ground coupled heat pump systems. American Society of Heating, Refrigerating and Air Conditioning Engineers, Atlanta, Georgia, p 312

Bozzoli F, Pagliarini G, Rainieri S, Schiavi L (2011) Estimation of soil and grout thermal properties through a TSPEP (two-step parameter estimation procedure) applied to TRT (thermal response test) data. Energy 36(2):839-846

Bruno R, Focaccia S, Tinti F (2011) Geostatistical modeling of a shallow geothermal reservoir for air conditioning of buildings. International Association of Mathematical Geoscience Congress, Salzburg, Austria, 5 - 9 September 2011

Chiles JP, Delfiner P (1999) Geostatistics: modeling spatial uncertainty. Wiley, New York

Eklof C, Gehlin S (1996) TED. A mobile equipment for geothermal response test, M.S. thesis. Lulea University of Technology, Lulea, Sweden, p 65

Eskilson P (1987) Thermal analysis of heat extraction boreholes. Department of Technical Physics, University of Lund, Sweden, p 264

Focaccia S, Tinti F, Bruno R (2013) A software tool for geostatistical analysis of thermal response test data: GA-TRT. Comput Geosci 59:163-170

Fujii H, Okubo H, Nishi K, Itoi R, Ohyam R, Shibata K (2010) An improved thermal response test for U-tube ground heat exchanger based on optical fiber thermometers. Geothermics 38(4):399-406

Gehlin S (2002) Thermal response test, Method, development and evaluation. Department of Environmental Engineering, University of Lulea, Sweden

Gehlin S (1998) Thermal response test. In situ measurements for thermal properties in hard rock. University of Lulea, Sweden

Gehlin S, Hellström G, Nordell B (2003) The influence of the thermosiphon effect on the thermal response test. Renew Energy 28:2239-2254 
Georgiev A, Busso A, Roth P (2006) Shallow borehole heat exchanger: response test and charging-discharging test with solar collectors. Renew Energy 31(7):971-985

Gustafsson AM, Westerlund L (2010) Multi-injection rate thermal response test in groundwater filled borehole heat exchanger. Renew Energy 35(5):1061-1070

Hellström G (1991) Thermal analysis of duct storage system. Dep. of Mathematical Physics University of Lund, Lund, Sweden, $\mathrm{p} 262$

IEA ECES Annex 21 Thermal Response Test (2013) Final Report November 2013

Ingersoll LR, Plass HJ (1948) Theory of the ground pipe heat source for the heat pump. ASHVE Trans 47:119-122

Liebel HT, Kilian H, Frengstad BJ, Ramstad RK, Brattli B (2012) Thermal response testing of a fractured hard rock aquifer with and without induced groundwater flow. Bull Eng Geol Environ 71(3):435-445

Li M, Lai ACK (2012) Parameter estimation of in-situ thermal response tests for borehole ground heat exchangers. Int J Heat Mass Trans 55(9-10):2615-2624

Lim K, Lee S, Lee C (2006) An experimental study on the thermal performance of ground heat exchanger. Exp Thermal Fluid Sci 31:985-990

Lund JW, Freeston DH, Boyd TL (2005) Worldwide direct-uses of geothermal energy 2005. Geothermics 34(6):691-727

Marcotte D, Pasquier P (2008) On the estimation of thermal resistance in borehole thermal conductivity test. Renew Energy 33:2407-2415

Matheron G (1967) Eléments Pour Une Théorie des Milieux Poreux. Masson et Cie, Paris

Matheron G (1971) Theory of regionalized variable and its applications. Les cahiers du Centre de Morphologie Mathématique de Fontainebleau. École des Mines de Paris: $n^{\circ}$ 5, Paris

Matheron G (1978) Estimer et choisir. Les cahiers du Centre de Morphologie Mathématique de Fontainebleau. École des Mines de Paris: $n^{\circ} 7$, Paris

Mattson N, Steinmann G, Laloui L (2008) Advanced compact design for the in situ determination of geothermal characteristics of soils. Energy Build 40(7):1344-1352

Mercuri S, Bruno R, Tinti F, Witte H (2013) Probabilistic approach to TRT analysis: evaluation of groundwater flow effects and machine - borehole interaction. European Geothermal Congress, Pisa, Italy, 3-7 June 2013

Mogensen P (1983) Fluid to duct wall heat transfer in duct system heat storage. Proc. Int. Conf. on subsurface heat storage in theory and practice. Stockholm, Sweden. June 6-8, p. 652-657

Raymond J, Therrien R, Gosselin B (2011) Borehole temperature evolution during thermal response tests. Geothermics 40:69-78

Sanner B, Karystas C, Mendrinos D, Rybach L (2003) Current status of ground source heat pumps and underground thermal energy storage in Europe. Geothermics 32:579-588

Schaetzle WJ (1980) Thermal energy storage in aquifers: design and applications. Elsevier Science \& Technology Books, 593 pp 177. Editor:Pergamon, Oxford, UK

Schiavi L (2009) 3D simulation of the thermal response test in a U-tube borehole heat exchanger. Proceedings of the COMSOL Conference 2009, Milan

Shargawy MH, Mokheimer EM, Badr HM (2009) Effective pipe-to-borehole thermal resistance for vertical ground heat exchangers. Geothermics 38:271-277

Signorelli S, Bassetti S, Pahud D, Kohl T (2007) Numerical evaluation of thermal response tests. Geothermics 36:141-166

Spitler JD (2005) Ground-source heat pump system research—past, present and future. Int J HVAC R Res 11:165-167

Urchueguía JF, Zacarés M, Corberán JM, Montero Á, Martos J, Witte H (2008) Comparison between the energy performance of a ground-coupled water to water heat pump system and an air to water heat pump system for heating and cooling in typical conditions of the European Mediterranean Coast. Energy Convers Manag 49:2917-2923

Van der Heijden F, Duin RPW, de Ridder D, Tax DMJ (2004) Classification, parameter estimation and state estimation - an engineering approach using MATLAB. Wiley, Chicester, p 45-79

Wagner R, Clauser C (2005) Evaluating thermal response tests using parameter estimation for thermal conductivity and thermal capacity. J Geophys Eng 2:349-356

Witte HJL, van Gelder AJ (2006) Geothermal response test using controlled multi-power level heating and cooling pulses (MPL-HCP): quantifying ground water effects on heat transport around a borehole heat exchanger. Ecostock 2006, 10th International Conference on Thermal Energy Storage. The Richard Stockton College of NewJersey.

Witte HJL (2012) Error analysis of thermal response tests. Appl Energy 109:302-311

Zanchini E, Terlizzese T (2008) Finite-element evaluation of thermal response test performed on U-tube borehole heat exchanger. Proceedings of COMSOL Conference, Hannover

\section{Submit your manuscript to a SpringerOpen ${ }^{\circ}$ journal and benefit from:}

- Convenient online submission

Rigorous peer review

- Immediate publication on acceptance

- Open access: articles freely available online

- High visibility within the field

- Retaining the copyright to your article

Submit your next manuscript at $\boldsymbol{\sim}$ springeropen.com 